Review

\title{
The Molecular Mechanisms of Zinc Neurotoxicity and the Pathogenesis of Vascular Type Senile Dementia
}

\section{Dai Mizuno $^{\dagger} *$ and Masahiro Kawahara ${ }^{\dagger}$}

Department of Bio Analytical Chemistry, Research Institute of Pharmaceutical Sciences,

Musashino University, Nishitokyo-shi, Tokyo 202-8585, Japan; E-Mail: makawa@musashino-u.ac.jp

$\dagger$ These authors contributed equally to this work.

* Author to whom correspondence should be addressed; E-Mail: d_mizuno@musashino-u.ac.jp; Tel./Fax: +81-424-689-335.

Received: 18 September 2013; in revised form: 18 October 2013 / Accepted: 22 October 2013 / Published: 7 November 2013

\begin{abstract}
Zinc ( $\mathrm{Zn})$ is an essential trace element that is abundantly present in the brain. Despite its importance in normal brain functions, excess $\mathrm{Zn}$ is neurotoxic and causes neurodegeneration following transient global ischemia and plays a crucial role in the pathogenesis of vascular-type dementia (VD). We have investigated the molecular mechanisms of Zn-induced neurotoxicity using immortalized hypothalamic neurons (GT1-7 cells) and found that carnosine ( $\beta$-alanyl histidine) and histidine (His) inhibited $\mathrm{Zn}^{2+}$-induced neuronal death. A DNA microarray analysis revealed that the expression of several genes, including metal-related genes (metallothionein and $\mathrm{Zn}$ transporter 1), endoplasmic reticulum (ER)-stress related genes (GADD34, GADD45, and $p 8$ ), and the calcium (Ca)-related gene Arc (activity-related cytoskeleton protein), were affected after $\mathrm{Zn}$ exposure. The co-existence of carnosine or His inhibited the expression of GADD34, $p 8$, and Arc, although they did not influence the expression of the metal-related genes. Therefore, ER-stress and the disruption of Ca homeostasis may underlie the mechanisms of Zn-induced neurotoxicity, and carnosine might be a possible drug candidate for the treatment of VD.
\end{abstract}

Keywords: Zinc; carnosine; histidine; vascular-type dementia 


\section{Introduction}

The prevalence of senile dementia, which is a serious problem in a rapidly aging world, increases with age. Approximately $25 \%$ of all elderly individuals are affected by the disease. In 2012, more than 3 million people in Japan were estimated to be affected by senile dementia, and the number continues to grow annually. Senile dementia is mainly divided into Alzheimer's disease (AD) and vascular-type dementia (VD). VD is a degenerative cerebrovascular disease, and its risk factors include age, the male gender, diabetes, and high blood pressure. The most common type of VD is caused by a series of small strokes or ischemia [1]. Following transient global ischemia or stroke, the interruption of blood flow and the resulting oxygen-glucose deprivation induces long-lasting membrane depolarization and an excessive release of glutamate into synaptic clefts. Thereafter, the excess glutamate causes an overstimulation of its receptors, namely $N$-methyl-D-aspartate (NMDA)-type receptors, amino-3-hydroxy-5-methyl-4-isoxazolepropionic acid (AMPA)-type receptors, and kainate-type receptors. Finally, $\mathrm{Ca}^{2+}$ dyshomeostasis, which involves the entry of large quantities of $\mathrm{Ca}^{2+}$ into glutamate-responsive neurons, triggers the delayed death of vulnerable populations of neurons, such as pyramidal neurons in the hippocampus - an area associated with learning and memory. Thereafter, the development of an infarct and subsequent cognitive dysfunction mark the pathogenesis of VD in elderly people. Approximately $30 \%$ of stroke patients show symptoms of dementia within 3 months of the initial stroke [2].

Increasing evidence has suggested that zinc $(\mathrm{Zn})$ is central to ischemia-induced neuronal death and, finally, to the pathogenesis of VD [3]. In ischemia conditions, a considerable amount of $\mathrm{Zn}$ (up to $300 \mu \mathrm{M}$ ) is co-related with glutamate into synaptic clefts by membrane depolarization. We have found that GT1-7 cells, which are immortalized hypothalamic neurons, are more vulnerable to Zn than other neuronal cells are [4,5]. Zn causes the apoptotic death of GT1-7 cells in a dose-dependent and time-dependent manner. Mellon et al. originally developed GT1-7 cells by genetically targeting tumorigenesis in mouse hypothalamic neurons [6]. The cells possess neuronal characteristics, such as the extension of neurites and the secretion or the expression of several neuron-specific proteins or receptors. Additionally, GT1-7 cells either lack, or possess low levels of, ionotropic glutamate receptors and do not exhibit glutamate toxicity [7]. These properties make the GT1-7 cell line an excellent model system for the investigation of Zn-induced neurotoxicity. Furthermore, we developed a screening system with GT1-7 cells with substances that protect neurons against Zn, based on the idea that such substances may be potential candidates for the treatment of VD [8-11]. Among the various food products or agricultural products we tested, we found that carnosine ( $\beta$-alanyl histidine) is markedly effective in preventing the neuronal death induced by $\mathrm{Zn} \mathrm{[12].} \mathrm{Carnosine} \mathrm{has} \mathrm{previously}$ been reported to be effective in the treatment of other neurodegenerative diseases, including AD and prion disease, or aging-related disorders, including cataracts [13-15].

In this article, we review the current understanding of the molecular mechanisms of $\mathrm{Zn}$-induced neurotoxicity and the link between $\mathrm{Zn}$ and the pathogenesis of VD. We also review the molecular mechanisms underlying the protective effects of carnosine in preventing neuronal death induced by Zn. 


\section{Zinc and Vascular-Type Dementia}

\subsection{Zinc-Induced Neurodegeneration after Ischemia}

$\mathrm{Zn}$ is an essential trace element for most organisms. It plays important roles in various physiological functions such as in mitotic cell division, immune system activity, the synthesis of proteins and nucleic acids, and as a co-factor of more than 300 enzymes or metalloproteins [16]. Recent studies have revealed that $\mathrm{Zn}$ signaling plays crucial roles in various human biological systems [17]. Zn deficiency in human childhood is known to cause dwarfism, the retardation of mental and physical development, immune dysfunction, and learning disabilities [18].

The human body contains approximately $2 \mathrm{~g}$ of $\mathrm{Zn}$, mostly in the testis, muscle, liver, and brain tissues. In the brain, $\mathrm{Zn}$ is found at the highest concentrations in the hippocampus, amygdala, cerebral cortex, thalamus, and olfactory cortex [19]. The total $\mathrm{Zn}$ content of the hippocampus has been estimated to be 70-90 ppm (dry weight). Although some $\mathrm{Zn}$ in the brain binds firmly to metalloproteins or enzymes, a substantial fraction (approximately $10 \%$ or more) either forms free $\mathrm{Zn}^{2+}$ or loosely bound $\mathrm{Zn}$, and it is histochemically detectable with staining with chelating reagents. This chelatable $\mathrm{Zn}$ is stored in the presynaptic vesicles of specific excitatory glutamatergic neurons, and it is secreted from those vesicles into synaptic clefts, along with glutamate, during neuronal excitation. Recent studies have suggested that secreted $\mathrm{Zn}^{2+}$ plays crucial roles in information processing, synaptic plasticity, learning, and memory. Indeed, $\mathrm{Zn}^{2+}$ has been shown to be essential in the hippocampus for the induction of long-term potentiation, a form of synaptic information storage that has become a well-known paradigm for the mechanisms underlying memory formation [20].

However, despite its importance, excess $\mathrm{Zn}$ is neurotoxic and has been implicated in neurodegenerative disease. $\mathrm{Zn}$ is shown in normal and ischemic conditions in the brain in Figure 1. In ischemic conditions, a considerable amount of $\mathrm{Zn}$ ( up to $300 \mu \mathrm{M}$ ) is associated with glutamate in synaptic clefts due to membrane depolarization. $\mathrm{Zn}$ causes the apoptotic death of primary cultured cortical neurons. Furthermore, chelatable $\mathrm{Zn}$ reportedly moves from presynaptic terminals into postsynaptic neuronal cell bodies. An increase in intracellular $\mathrm{Zn}^{2+}$ levels $\left(\left[\mathrm{Zn}^{2+}\right]_{\mathrm{i}}\right)$, namely, $\mathrm{Zn}$ translocation, occurs in vulnerable neurons in the CA1 or CA3 regions of the hippocampus prior to the onset of delayed neuronal death after transient global ischemia [21]. This $\mathrm{Zn}$ translocation has been reported to enhance the appearance of infarcts. The administration of calcium ethylenediaminetetraacetic acid (Ca-EDTA), a membrane-impermeable chelator that chelates cations other than $\mathrm{Ca}$, has been shown to block the translocation of $\mathrm{Zn}$, protect hippocampal neurons after transient global ischemia, and reduce infarct volume [22]. Thus, $\mathrm{Zn}$ translocation has been recognized as the primary event in the pathway of $\mathrm{Zn}$-induced neuronal death. Sensi et al. have observed temporal changes in $\left[\mathrm{Zn}^{2+}\right]_{\mathrm{i}}$ in cultured cortical neurons with a $\mathrm{Zn}$-sensitive fluorescent dye; those results revealed that at least 3 major routes of $\mathrm{Zn}^{2+}$ entry have been identified: Voltage-gated $\mathrm{Ca}^{2+}$ channels (VGLG), NMDA-type glutamate receptors, and AMPA/kainate-type glutamate receptors (A/K-R). Although the NMDA-type glutamate receptors are present in most neurons, the permeability of $\mathrm{Zn}^{2+}$ and $\mathrm{Ca}^{2+}$ through AMPA/kainate channels is greater than that of NMDA-type glutamate receptor channels [23]. 
Figure 1. $\mathrm{Zn}$ in normal or pathological conditions in the brain. Under normal conditions (A), neuronal excitation causes the release of glutamate and $\mathrm{Zn}$. Zn regulates postsynaptic excitability by binding to NMDA-type glutamate receptors (NMDA-R). However, under pathological conditions, such as ischemia $(\mathbf{B})$, oxygen-glucose deprivation induces the release of excess glutamate, as well as $\mathrm{Zn}$, into the synaptic cleft. Excess $\mathrm{Zn}$ enhances the expression of Ca-AMPA/kainate channels ( $\mathrm{Ca}-\mathrm{A} / \mathrm{K}-\mathrm{R})$, and it is translocated through the $\mathrm{Ca}-\mathrm{A} / \mathrm{K}-\mathrm{R}$ or through other pathways, such as voltage-gated L-type $\mathrm{Ca}^{2+}$ channels (VGLC), into the target neuron, where $\mathrm{Zn}$ acts to inhibit various enzymes, inhibit mitochondrial respiration, cause energy depletion, and produce ROS. Excess glutamate induces an increase in intracellular $\mathrm{Ca}^{2+}$ levels in the target neuron. Increased levels of intracellular $\mathrm{Ca}^{2+}$ then trigger various apoptotic pathways, such as those involving the activation of calpain or caspases, or other enzymatic pathways related to apoptosis; ultimately, this leads to neuronal death.

(A) Normal condition

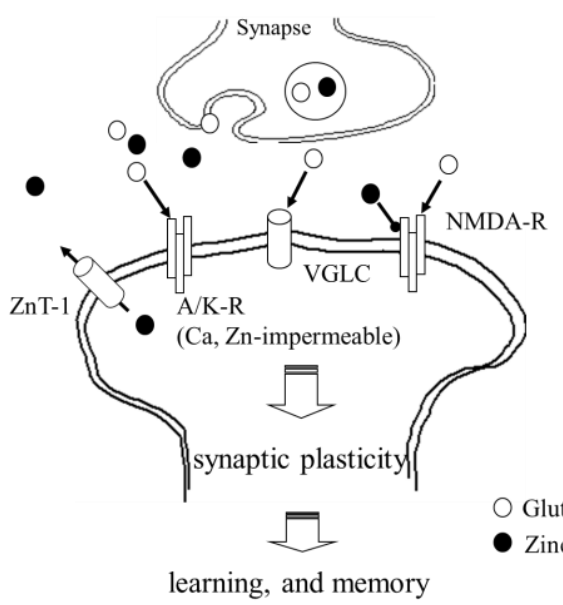

(B) After ischemia
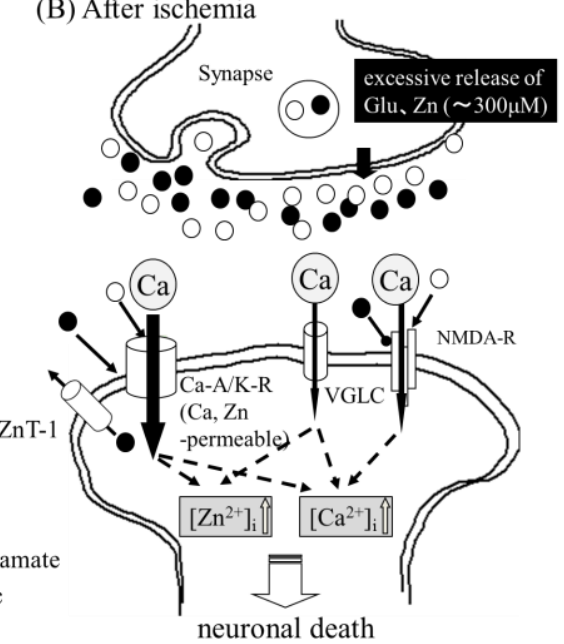

In normal conditions, most hippocampal neurons express AMPA receptors with GluR2 subunits, which are poorly permeable to divalent cations, including $\mathrm{Ca}^{2+}$ and $\mathrm{Zn}^{2+}(\mathrm{A} / \mathrm{K}-\mathrm{R})$. However, under ischemic conditions, an acute reduction in the expression of the GluR2 subunit occurs, and neurons possess specific types of AMPA receptors in which the channels are directly $\mathrm{Ca}^{2+}$ permeable (Ca-AMPA/kainate channels; Ca-A/K-R) [24]. The appearance of $\mathrm{Ca}-\mathrm{A} / \mathrm{K}-\mathrm{R}$ causes an increased permeability of $\mathrm{Ca}^{2+}$ and enhances the toxicity. Therefore, the expression of $\mathrm{Zn}^{2+}$-permeable Ca-A/K-R and the entry of $\mathrm{Ca}^{2+}$ and/or $\mathrm{Zn}^{2+}$ through the channels are involved in delayed neuronal death after ischemia. Considering that Ca-EDTA, a Zn chelator, attenuates the ischemia-induced downregulation of the GluR2 gene [22], Zn has also been implicated in the transcriptional regulation of Ca-A/K-R.

These results strongly implicate $\mathrm{Zn}$ as a key player in delayed neuronal death after transient global ischemia, a process that might be involved in the pathogenesis of VD [25,26]. The accumulation of $\mathrm{Zn}$ has also been observed following head trauma and epilepsy [27], implying that $\mathrm{Zn}$ neurotoxicity might underlie the pathological mechanisms of various injuries. Moreover, the disruption of $\mathrm{Zn}$ homeostasis has also been implicated in other neurodegenerative diseases, including AD [28-30], prion disease [31], amyotrophic lateral sclerosis [32], and Wilson's disease [33]. Thus, Zn might play a role 
like that of Janus, who is the ancient Roman god of doorways and who has 2 different faces, in the brain: Both Zn depletion and excess Zn cause severe damage to neurons.

\subsection{Molecular Mechanism of Zn-Induced Neuronal Neath: GT1-7 Cells as an In Vitro Model System}

Understanding the molecular mechanisms of $\mathrm{Zn}$-induced neuronal death is of great importance for the treatment of VD. Numerous studies have been undertaken in order to elucidate the mechanisms of $\mathrm{Zn}$-induced neuronal death. To this end, many researchers have investigated $\mathrm{Zn}$ neurotoxicity in vitro mainly by using primary cultured neurons from rat cerebral cortex or hippocampus [34] or PC-12 cells, a pheochromocytoma cell line [35]. However, the roles of $\mathrm{Zn}$ are highly complex. For example, $\mathrm{Zn}$ has been shown to inhibit NMDA-type glutamate receptors and to regulate the excitability of glutamatergic neurons, which are toxic to neurons. Therefore, distinguishing the effects of $\mathrm{Zn}$ and glutamate in neuronal cells that possess glutamate receptors has proven difficult.

We found that GT1-7 cells, which are immortalized hypothalamic neurons, are much more sensitive to $\mathrm{Zn}$ than other neuronal cells are [4,5]. Figure 2 shows the viability of GT1-7 cells, PC-12 cells, B-50 cells (a neuroblastoma cell line), and primary cultured neurons derived from the rat cerebral cortex or hippocampus following exposure to $\mathrm{Zn}$. $\mathrm{Zn}$ caused the apoptotic death of GT1-7 cells in a dose-dependent and time-dependent manner. The degenerated GT1-7 cells are terminal deoxynucleotidyl transferase-mediated biotinylated UTP nick-end labeling (TUNEL)-positive and exhibit DNA fragmentation [4,5].

Figure 2. Apoptotic death of GT1-7 cells after exposure to Zn. Viability of various neuronal cells after exposure to Zn. Cultured neuronal cells (GT1-7 cells, PC-12 cells, B-50 cells (a neuroblastoma cell line), primary cultured neurons of the rat cerebral cortex, and primary cultured neurons of the rat hippocampus) were administered $50 \mu \mathrm{M}$ of $\mathrm{Zn}$. After $24 \mathrm{~h}$, cell viability was analyzed by the WST-1 method.

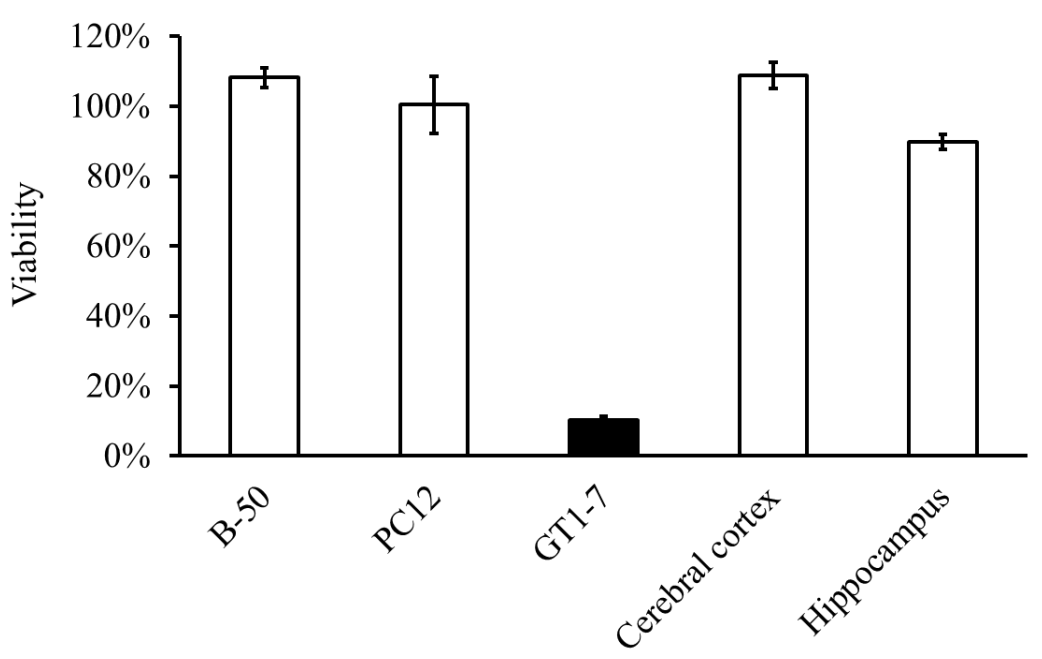

The GT1-7 cells, which were developed by genetically targeting the tumorigenesis of mouse hypothalamic neurons, possess a number of neuronal characteristics, such as the extension of neurites, the secretion of gonadotropin-releasing hormone $(\mathrm{GnRH})$, and expression of neuron-specific proteins or receptors including microtubule-associated protein 2 (MAP2), tau protein, neurofilament, 
synaptophysin, $\mathrm{GABA}_{\mathrm{A}}$ receptors, dopamine receptors, and L-type $\mathrm{Ca}^{2+}$ channels [6]. Additionally, GT1-7 cells either lack or possess low levels of ionotropic glutamate receptors and do not exhibit glutamate toxicity [7]. These properties make the GT1-7 cell line an excellent model system for the investigation of $\mathrm{Zn}$-induced neurotoxicity.

\subsection{Implication of Ca Dyshomeostasis in Zn-Induced Neuron Death}

We investigated the detailed characteristics and mechanisms of Zn-induced death in GT1-7 cells. Previously, we tested the effects of the administration of various pharmacological agents prior to the $\mathrm{Zn}$ treatment of GT1-7 cells. We showed that the administration of sodium pyruvate, an energy substrate, significantly inhibited the Zn-induced death of GT1-7 cells [4]. The results were consistent with findings of other studies that used primary cultured cortical neurons, oligodendrocyte progenitor cells, or retinal cells. Furthermore, the administration of pyruvate attenuated neuronal death after ischemia in vivo [36]. Shelline and his colleagues have reported that $\mathrm{Zn}$ exposure decreases the levels of $\mathrm{NAD}^{+}$and ATP in cultured cortical neurons and that treatment with pyruvate restores the $\mathrm{NAD}^{+}$ levels [37]. An imaging study that used a Zn-sensitive fluorescent dye and a mitochondrial marker revealed that $\mathrm{Zn}$ is localized within mitochondria. $\mathrm{Zn}$ has been reported to inhibit various mitochondrial enzymes and the intracellular trafficking of mitochondria. It has also been reported that $\mathrm{Zn}$ produces reactive oxygen species and causes oxidative damage resulting from mitochondrial impairments. Therefore, energy failure and the inhibition of glycolysis in mitochondria may be involved in Zn neurotoxicity [38].

Figure 3. Effects of various pharmacological substances on the $\mathrm{Zn}$-induced death of GT1-7 cells. (A) GT1-7 cells were exposed to $50 \mu \mathrm{M}$ of $\mathrm{Zn}^{2+}$ with agonists or antagonists of neurotransmitters [glutamate, D-APV (D-2-amino-5-phosphonovalerate), CNQX (6-cyano-7-nitroquinoxaline-2,3-dione), muscimol, baclofen, bicuculline], GABA channel blockers [TTX (tetrodotoxin), nimodipine], etc. (B) The relative viability of GT1-7 cells exposed to $\mathrm{Zn}^{2+}$ with or without $\mathrm{Ca}^{2+}$.
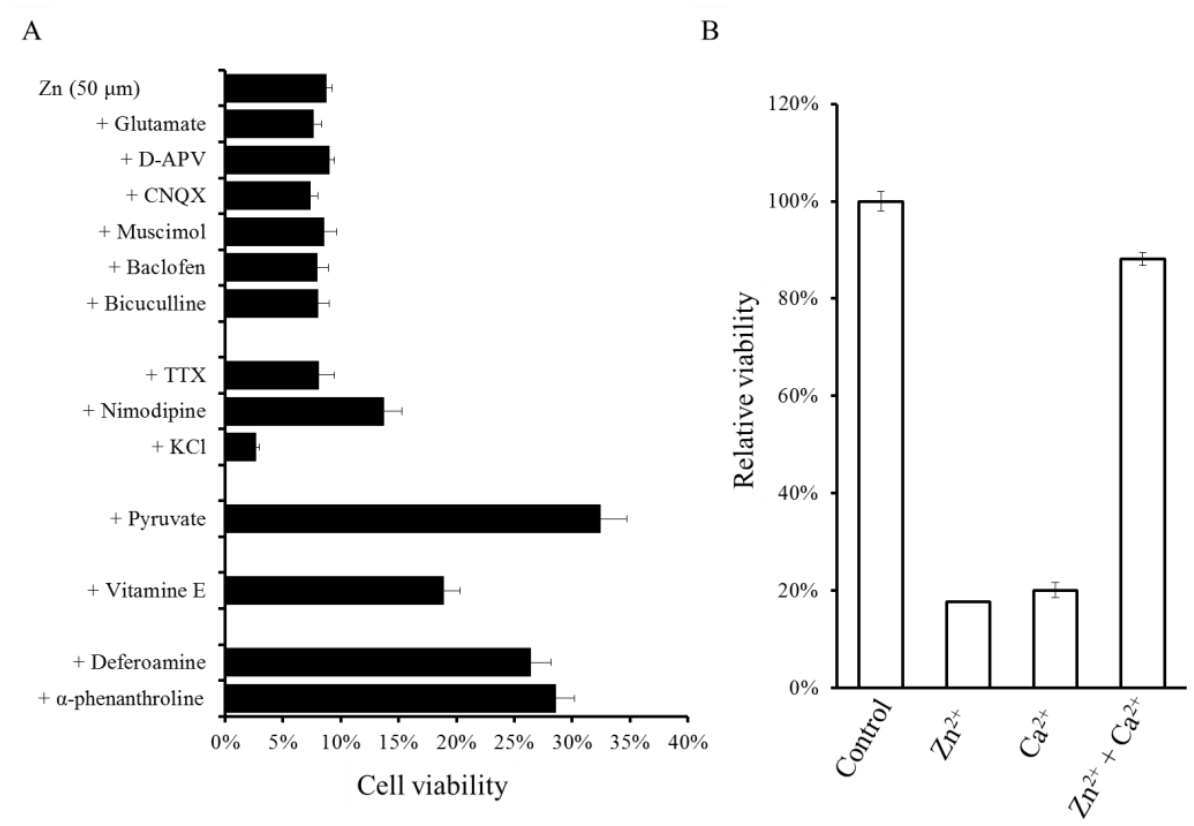
Neither antagonists nor agonists of excitatory neurotransmitters [D2-amino-5-phosphonovalerate (APV), glutamate, and 6-cyano-7-nitroquinoxaline-2,3-dione(CNQX)], or those of inhibitory neurotransmitters (bicuculline, muscimol, baclofen, and GABA) attenuated the viability of GT1-7 cells after Zn exposure (Figure 3). Our findings in GT1-7 cells were inconsistent with previous studies that found that agonists of glutamate receptors, such as NMDA or AMPA, enhance Zn-induced neurotoxicity in cultured cortical neurons [39].

The co-exposure of GT1-7 cells to various metal ions with Zn has shown the involvement of other metal ions in $\mathrm{Zn}$ neurotoxicity [40]. The equivalent molar addition of $\mathrm{Al}^{3+}$ and $\mathrm{Gd}^{3+}$ significantly inhibited $\mathrm{Zn}$-induced neuronal death. Moreover, the overloading of $\mathrm{Ca}^{2+}$ and $\mathrm{Mg}^{2+}$ inhibited the Zn-induced death of GT1-7 cells, and Zn protected GT1-7 cells from the neurotoxicity induced by $\mathrm{Ca}^{2+}$ overload and vice versa (Figure $3 \mathrm{~B}$ ).

Considering the implication of $\mathrm{Zn}$ in transient global ischemia, substances that protect against Zn-induced neuronal death could be potential candidates for the prevention or treatment of neurodegeneration following ischemia and ultimately provide a lead for treatments for VD. We examined the potential inhibitory effects of various agricultural products, such as vegetable extracts, fruits extracts, and fish extracts, and found that extracts from eel muscles significantly protected against Zn-induced neurotoxicity [9]. Finally, we determined that carnosine, a small hydrophilic peptide abundant in eel muscles, protected GT1-7 cells from Zn-induced neurotoxicity in a dose-dependent manner (Figure 4).

Figure 4. Protective activity against the Zn-induced neurotoxicity of carnosine and its stability in culture media. The protective activity of carnosine on $\mathrm{Zn}$-induced death in GT1-7 cells. $\mathrm{ZnCl}_{2}(30 \mu \mathrm{M})$ was pre-administered to the GT1-7 cells. After $24 \mathrm{~h}$, the viability of the GT1-7 cells was compared with the co-administration of various concentrations of carnosine. The data are presented as means \pm S.E.M., $n=6$. ${ }^{*} p<0.01$, $* * p<0.005$.

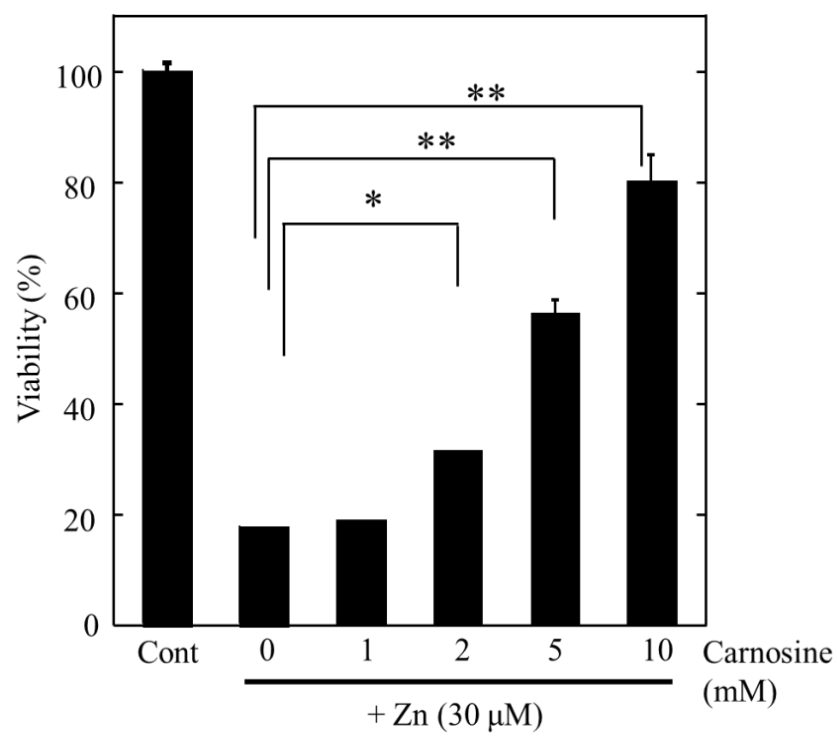

Based on these findings, we investigated the molecular mechanisms underlying Zn-induced neurotoxicity. Our results suggested that $\mathrm{Ca}$ dyshomeostasis may be involved in the mechanisms of 
Zn-induced neurotoxicity. It has also been reported that Zn neurotoxicity in PC12 cells is attenuated by an L-type $\mathrm{Ca}^{2+}$-channel blocker, nimodipine, and enhanced by an L-type $\mathrm{Ca}^{2+}$ channel activator, $\mathrm{S}(-)$-Bay K 8466 [35]. Additionally, $\mathrm{Zn}$ neurotoxicity is attenuated by aspirin, which prevents $\mathrm{Zn}^{2+}$ entry through voltage-gated $\mathrm{Ca}^{2+}$ channels [41]. In addition to this issue, we employed a high-resolution multi-site video imaging system with fura-2 as the cytosolic-free $\mathrm{Ca}$ reporter fluorescent probe in order to observe the temporal changes in $\left[\mathrm{Ca}^{2+}\right]_{\mathrm{i}}$ after exposure to $\mathrm{Zn}$ [5]. $\mathrm{Zn}$ caused increased $\left[\mathrm{Ca}^{2+}\right]_{\mathrm{i}}$ among GT1-7 cells after 3-30 min of exposure [5]. A detailed analysis of $\mathrm{Zn}$-induced $\left[\mathrm{Ca}^{2+}\right]_{\mathrm{i}}$ revealed that the pretreatment of $\mathrm{Al}^{3+}$ significantly blocked the $\mathrm{Zn}$-induced $\left[\mathrm{Ca}^{2+}\right]_{\mathrm{i}}$ increases. Thus, it is possible that $\mathrm{Al}^{3+}$, a known blocker of various types of $\mathrm{Ca}^{2+}$ channels, might attenuate $\mathrm{Zn}$-induced neurotoxicity by blocking $\mathrm{Zn}$-induced increases in $\left[\mathrm{Ca}^{2+}\right]_{\mathrm{i}}$.

\subsection{Altered Gene Expression during Zinc-Induced Neurotoxicity}

Moreover, we investigated the alterations in gene expression during Zn-induced neurotoxicity with a DNA microarray and RT-PCR [42]. The expression of several genes, including metal-related genes, such as metallothionein (MT)-1, MT-2, and the Zn transporter 1 (ZnT-1) were induced by Zn exposure. Metallothioneins are intracellular polypeptides with a remarkable ability to bind metallic ions. MT1 and MT2 play roles in the detoxification of heavy metals. Zn-specific membrane transporter proteins (Zn transporters) also control $\mathrm{Zn}$ homeostasis; they facilitate $\mathrm{Zn}$ influx during deficiencies and efflux during $\mathrm{Zn}$ excess. Thus, these proteins are upregulated by increases in $\left[\mathrm{Zn}^{2+}\right]_{i}$. (see $\mathrm{Zn}$ in Figure 5). Furthermore, our investigation into the changes in gene expression during $\mathrm{Zn}$-induced neuronal death revealed an upregulation of several genes, including ER stress-related genes [growth-arrest DNA damage $(G A D D) 34, G A D D 45$, and $p 8$ ) and the $\mathrm{Ca}^{2+}$-related gene $A r c$ (activity-related cytoskeleton protein) [42]. These findings are important considering the involvement of $\mathrm{Ca}^{2+}$ homeostasis in Zn-induced neurotoxicity. It is widely accepted that the ER regulates the levels of $\left[\mathrm{Ca}^{2+}\right]_{\mathrm{i}}$ and that ER stress causes the apoptotic death of various cells by the accumulation of unfolded or misfolded proteins [43]. Emerging evidence has implicated ER stress in the pathogenesis of various neurodegenerative diseases, including AD, Parkinson's disease, prion diseases, and ischemia-induced neurodegeneration [44,45]. In particular, GADD34 and GADD45 are the genes of the sensor proteins of ER stress, and they are induced by DNA damage and have been implicated in DNA repair and tumorigenesis [46]. The $p 8 \mathrm{mRNA}$ is induced in response to divergent stress, and it might be involved in tumorigenesis [47]. In addition, $A r c$ is a gene that encodes a protein that exists in dendrites and plays crucial roles in synaptic plasticity and memory consolidation. Arc expression is induced by the increased neuronal activity that occurs in response to learning and by brain-derived neurotrophic factor (BDNF) [48].

The coexistence of Ca-EDTA abolished the effects of $\mathrm{Zn}$ in the expression of these genes (see $\mathrm{Zn}+$ Ca-EDTA in Figure 5). Meanwhile, the addition of carnosine and histidine (His) did not influence the upregulation of MT1, MT2, or ZnT-1 during Zn-induced neurotoxicity (see $\mathrm{Zn}+$ Carnosine, $\mathrm{Zn}+$ His in Figure 5). However, the coexposure of GT1-7 cells to carnosine and His with Zn inhibited the expression of GADD34, GADD45, $p 8$ and Arc induced by $\mathrm{Zn}$ exposure (Figure 5). These attenuations of carnosine and His on the $\mathrm{Zn}$-induced expression of these genes may affect ER stress-related or Arc-related apoptotic pathways. 
Figure 5. Effects of carnosine and His on Zn-induced gene expression. GT1-7 cells were exposed to $50 \mu \mathrm{M}$ of $\mathrm{ZnCl}_{2}$ for $6 \mathrm{~h}$ in the presence or absence of Ca-EDTA $(0.5 \mathrm{mM})$, His $(1.0 \mathrm{mM})$, or carnosine $(2.0 \mathrm{mM})$. The expression of various genes were analyzed by RT-PCR and the gene expression levels were normalized against $\beta$-actin. The data are expressed as means \pm S.E.M., $n=3$. ${ }^{*} p<0.01$ vs. $\mathrm{Zn}$.

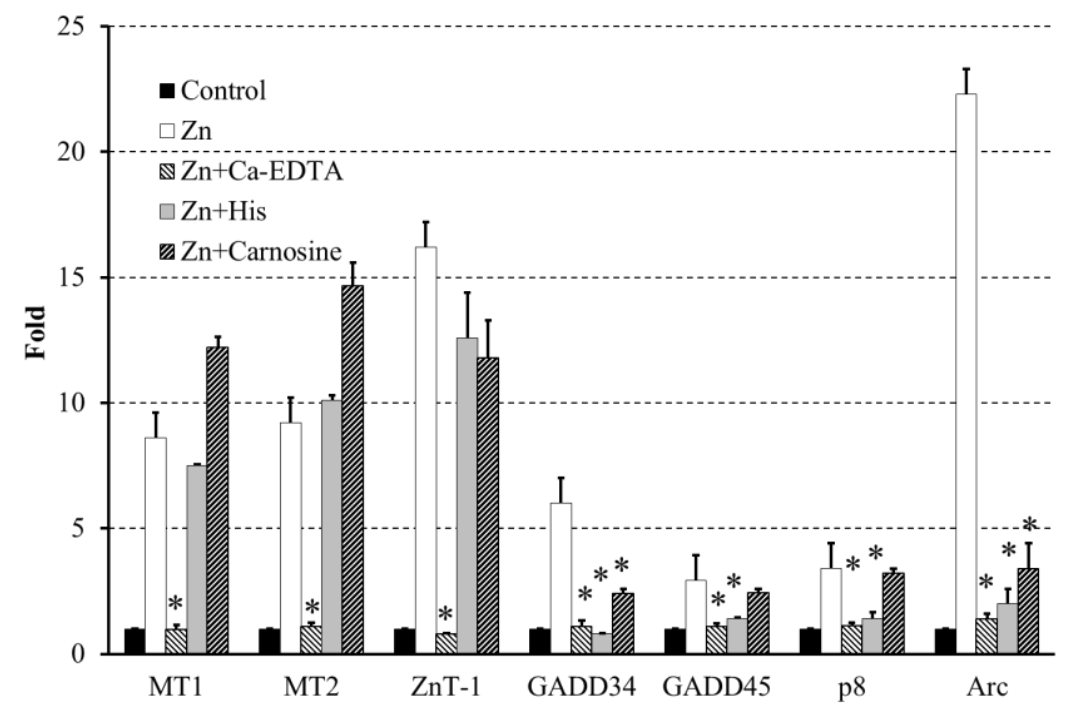

\section{Hypothesis Regarding Zn-Induced Neurotoxicity}

Collectively considering the accumulated evidence presented in this paper, we inferred a scheme for $\mathrm{Zn}$ neurotoxicity and the role of carnosine (Figure 6). In normal conditions, neuronal excitation causes the release of glutamate and $\mathrm{Zn}$. However, $\mathrm{Zn}$ regulates postsynaptic excitability by binding to NMDA-type glutamate receptors. $\mathrm{Zn}$ in the synaptic clefts is either taken up, absorbed, or bound to the carnosine released from glial cells by the stimuli of glutamate and $\mathrm{Zn}$. This feedback pathway of carnosine- $\mathrm{Zn}$ protects neurons against both glutamate toxicity and $\mathrm{Zn}$ toxicity. However, in pathological conditions, such as ischemia, oxygen-glucose deprivation induces the release of excess glutamate, as well as $\mathrm{Zn}$, into synaptic clefts (Figure 1B). Excess $\mathrm{Zn}$ enhances the expression of $\mathrm{Ca}-\mathrm{A} / \mathrm{K}-\mathrm{R}$, and it is translocated through the $\mathrm{Ca}-\mathrm{A} / \mathrm{K}-\mathrm{R}$ or through other pathways into the target neuron, where $\mathrm{Zn}$ acts to inhibit various enzymes, inhibit mitochondrial respiration, cause energy depletion, and/or produce reactive oxygen species. Excess glutamate induces an increase in the intracellular $\mathrm{Ca}^{2+}$ levels in the target neuron. Increased levels of intracellular $\mathrm{Ca}^{2+}$ then trigger various apoptotic pathways, such as those involving the activation of calpain or the activation of caspases, or other enzymatic pathways related to apoptosis; ultimately, this leads to neuronal death. Zn also influences intracellular $\mathrm{Ca}^{2+}$ levels and enhances the effects of glutamate. Our results of the Zn-induced upregulation of GADD34, GADD45, p8, and Arc suggest the implication of some ER stress-related or $A r c$-related pathways in ischemia-induced neuronal death and the pathogenesis of VD. This hypothesis is supported by the findings that the expression of GADD34, GADD45, and Arc was induced after ischemia [49-51]. 
Figure 6. Hypothetical schematic of the molecular mechanisms of the protective effects of carnosine in preventing the neuronal death induced by $\mathrm{Zn}$. Carnosine is synthesized in glial cells and is secreted in response to stimulation by glutamate and $\mathrm{Zn}$; it protects neurons from $\mathrm{Zn}$ neurotoxicity. Carnosine inhibits the expression of ER stress-related genes and Arc, which are induced by $\mathrm{Zn}$ exposure. It is plausible that carnosine may be transported into cell bodies, where it can inhibit ER stress-related and/or Arc-related apoptotic pathways activated by $\mathrm{Zn}$.

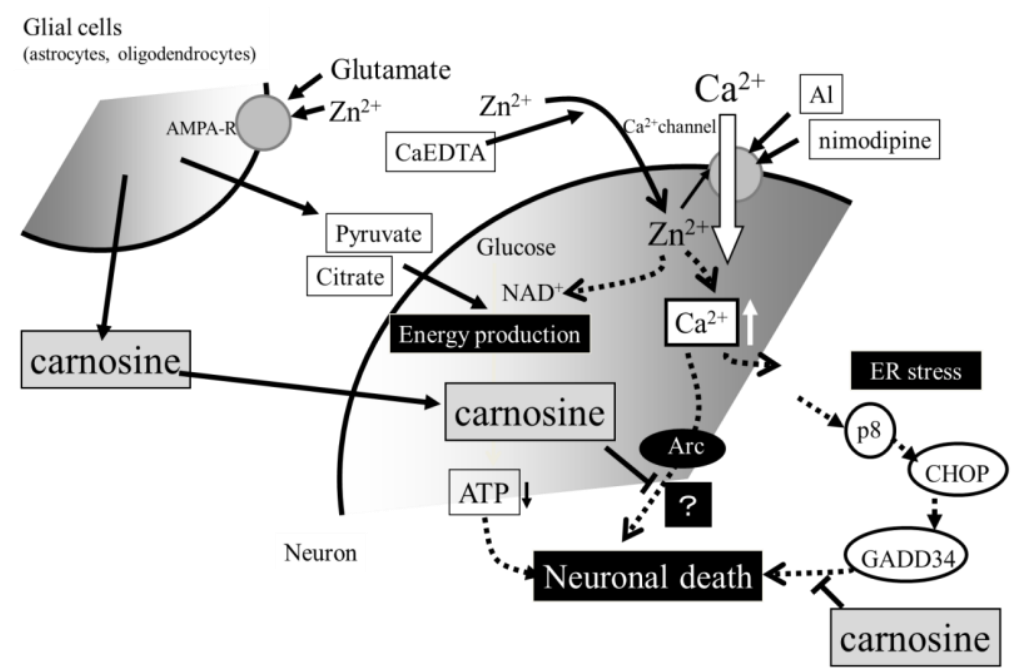

\section{Conclusions}

Our results suggest the involvement of $\mathrm{Ca}^{2+}$ homeostasis and the gene expression of ER-stress related genes or Arc in $\mathrm{Zn}$-induced neurotoxicity. These findings are important considering that $\mathrm{Ca}^{2+}$ homeostasis is involved in other neurodegenerative diseases including Alzheimer's disease, prion diseases, Parkinson's disease, ALS etc. Interestingly, $\mathrm{Zn}$ is involved in the pathogenesis of these neurodegenerative diseases and acts as a contributor of the disease in one part, and as a protector in another part. Thus, Zn might play a role like that of Janus, an ancient Roman god of doorways with two different faces, in the brain. Therefore, our hypothesis may help the understanding of VD as well as other neurodegenerative diseases.

Our results also indicate the relevance of carnosine and His for consideration in the treatment of VD. Carnosine, which is a naturally occurring dipeptide, is commonly present in vertebrate tissues, particularly within the skeletal muscles and nervous tissues [15]. It is found at high concentrations in the muscles of animals or fish that exhibit high levels of exercise, such as horses, chickens, and whales. The concentrations of carnosine in the muscles of such animals have been estimated to be 50-200 mM, and carnosine is believed to play important roles in the buffering capacities of muscle tissue. During high-intensity anaerobic exercise, proton accumulation causes a decrease in intracellular $\mathrm{pH}$, which influences various metabolic functions. The $\mathrm{pKa}$ value of carnosine is 7.01 , which is close to intracellular $\mathrm{pH}$. Therefore, carnosine contributes to physicochemical nonbicarbonate buffering in skeletal muscles, and the administration of carnosine has been reported to induce hyperactivity in animals. 
Carnosine reportedly has various functions, including anti-oxidant, anti-glycation, and anti-crosslinking functions, and it is considered to be an endogenous neuroprotective and anti-aging substance. Considering the advantageous properties of carnosine (relatively nontoxic, heat-stable, and water-soluble), dietary supplementation of carnosine might be an effective strategy for the prevention or treatment of neurodegenerative diseases, such as ischemia, VD, AD, and prion diseases. Corona et al. have reported that the supplementation of carnosine improved the learning abilities of Alzheimer's model mice [13]. We have demonstrated that the neurotoxicity of the prion protein fragment is attenuated by $\mathrm{Zn}$ and carnosine [14]. Therefore, we applied for patents for carnosine as a drug for the treatment of VD or for slowing the progress of cognitive decline after ischemia (application No. 2006-145857; publication No. 2007-314467 in Japan) [12] and for His (application No. 2008-098675; publication No. 2009-249335 in Japan). Thus, further research into the role of $\mathrm{Zn}$ in neuronal injury and the significance of $\mathrm{Zn}$ and $\mathrm{Ca}$ homeostasis might lead to the development of new treatments for VD.

In the brain, carnosine also exists in the olfactory bulb [52]. We have developed a high-performance liquid chromatography system for analyzing and quantifying carnosine [10] and have confirmed that carnosine is abundant in the olfactory bulb in the rat brain. Although the physiological roles of carnosine in the olfactory bulb are still unclear, olfactory bulb neurons are less sensitive to damage after ischemia compared to hippocampal neurons, in spite of the accumulation of Zn. Furthermore, the contents of carnosine have been shown to vary during development [53], and the content of carnosine in muscle is decreased in aged animals [54]. Therefore, carnosine may play protective roles in Zn-induced neurodegeneration after ischemia in the olfactory bulb. It is plausible that carnosine may be transported into cell bodies, where it can inhibit several apoptotic pathways activated by $\mathrm{Zn}$ (Figure 6).

\section{Acknowledgments}

The authors would like to thank Masayuki Yanagita, Ayumi Komuro, and Naoko Kato for their technical assistance. This work was partially supported by a Grant-in Aid for Scientific Research from the Ministry of Education, Culture, Sports, Science and Technology of Japan and by a Grant from Cooperation for Innovative Technology and Advanced Research in Evolutional Area (CITY AREA) from the Miyazaki Prefectural Industrial Support Foundation.

\section{Conflicts of Interest}

The authors declare no conflict of interest.

\section{References}

1. Lee, J.M.; Grabb, M.C.; Zipfel, G.J.; Choi, D.W. Brain tissue responses to ischemia. J. Clin. Invest. 2000, 106, 723-731.

2. De Haan, E.H.; Nys, G.M.; van Zandvoort, M.J. Cognitive function following stroke and vascular cognitive impairment. Curr. Opin. Neurol. 2006, 19, 559-564. 
3. Weiss, J.H.; Sensi, S.L.; Koh, J.Y. $\mathrm{Zn}^{2+}$ : A novel ionic mediator of neural injury in brain disease. Trends Pharmacol. Sci. 2000, 21, 395-401.

4. Kawahara, M.; Kato-Negishi, M.; Kuroda, Y. Pyruvate blocks zinc-induced neurotoxicity in immortalized hypothalamic neurons. Cell Mol. Neurobiol. 2002, 22, 87-93.

5. Koyama, H.; Konoha, K.; Sadakane, Y.; Ohkawara, S.; Kawahara, M. Zinc neurotoxicity and the pathogenesis of vascular-type dementia: Involvement of calcium dyshomeostasis and carnosine. J. Clin. Toxicol. 2011, S3, doi:10.4172/2161-0495.S3-002.

6. Mellon, P.L.; Windle, J.J.; Goldsmith, P.C.; Padula, C.A.; Roberts, J.L.; Weiner, R.I. Immortalization of hypothalamic GnRH neurons by genetically targeted tumorigenesis. Neuron 1990, 5, 1-10.

7. Mahesh, V.B.; Zamorano, P.; De Sevilla, L.; Lewis, D.; Brann, D.W. Characterization of ionotropic glutamate receptors in rat hypothalamus, pituitary and immortalized gonadotropin-releasing hormone (GnRH) neurons (GT1-7 cells). Neuroendocrinology 1999, 69, 397-407.

8. Sadakane, Y.; Konoha, K.; Kawahara, M. Protective activity of mango (Mangifera indica L.) fruit against a zinc-induced neuronal cell death is independent of its antioxidant activity. Trace Nutr. Res. 2005, 22, 73-79.

9. Konoha, K.; Sadakane, Y.; Kawahara, M. Carnosine protects GT1-7 cells against zinc-induced neurotoxicity: A possible candidate for treatment for vascular type of dementia. Trace Nutr. Res. 2006, 23, 56-62.

10. Sadakane, Y.; Konoha, K.; Nagata, T.; Kawahara, M. Protective activity of the extracts from Japanese eel (Anguilla japonica) against zinc-induced neuronal cell death: Carnosine and an unknown substance. Trace Nutr. Res. 2007, 24, 98-105.

11. Sadakane, Y.; Konoha, K.; Nagata, T.; Kawahara, M. Improvement of screening for protective substances against zinc-induced neuronal cell death. Trace Nutr. Res. 2008, 25, 41-45.

12. Kawahara, M.; Konoha, K.; Nagata, T.; Sadakane, Y. Protective substances against zinc-induced neuronal death after ischemia: Carnosine a target for drug of vascular type of dementia. Recent Pat. CNS Drug Discov. 2007, 2, 145-149.

13. Corona, C.; Frazzini, V.; Silvestri, E.; Lattanzio, R.; La Sorda, R.; Piantelli, M.; Canzoniero, L.M.; Ciavardelli, D.; Rizzarelli, E.; Sensi, S.L. Effects of dietary supplementation of carnosine on mitochondrial dysfunction, amyloid pathology, and cognitive deficits in 3xTg-AD mice. PLoS One 2011, 6, e17971.

14. Kawahara, M.; Koyama, H.; Nagata, T.; Sadakane, Y. Zinc, copper, and carnosine attenuate neurotoxicity of prion fragment PrP106-126. Metallomics 2011, 3, 726-734.

15. Hipkiss, A.R. Carnosine and its possible roles in nutrition and health. Adv. Food Nutr. Res. 2009, 57, 87-154.

16. Hambidge, M. Human zinc deficiency. J. Nutr. 2000, 130, 1344S-1349S.

17. Hirano, T.; Murakami, M.; Fukada, T.; Nishida, K.; Yamasaki, S.; Suzuki, T. Roles of zinc and zinc signaling in immunity: Zinc as an intracellular signaling molecule. Adv. Immunol. 2008, 97, 149-176.

18. Prasad, A.S. Impact of the discovery of human zinc deficiency on health. J. Am. Coll. Nutr. 2009, 28, 257-265. 
19. Frederickson, C.J.; Suh, S.W.; Silva, D.; Frederickson, C.J.; Thompson, R.B. Importance of zinc in the central nervous system: The zinc-containing neuron. J. Nutr. 2000, 130, 1471S-1483S.

20. Tamano, H.; Takeda, A. Dynamic action of neurometals at the synapse. Metallomics 2011, 3, 656-661.

21. Koh, J.Y.; Suh, S.W.; Gwag, B.J.; He, Y.Y.; Hsu, C.Y.; Choi, D.W. The role of zinc in selective neuronal death after transient global cerebral ischemia. Science 1996, 272, 1013-1016.

22. Calderone, A.; Jover, T.; Mashiko, T.; Noh, K.M.; Tanaka, H.; Bennett, M.V.; Zukin, R.S. Late calcium EDTA rescues hippocampal CA1 neurons from global ischemia-induced death. J. Neurosci. 2004, 24, 9903-9913.

23. Sensi, S.L.; Canzoniero, L.M.; Yu, S.P.; Ying, H.S.; Koh, J.Y.; Kerchner, G.A.; Choi, D.W. Measurement of intracellular free zinc in living cortical neurons: Routes of entry. J. Neurosci. 1997, 17, 9554-9564.

24. Pellegrini-Giampietro, D.E.; Gorter, J.A.; Bennett, M.V.; Zukin, R.S. The GluR2 (GluR-B) hypothesis: $\mathrm{Ca}^{2+}$-permeable AMPA receptors in neurological disorders. Trends Neurosci. 1997, 20, 464-470.

25. Plum, L.M.; Rink, L.; Haase, H. The essential toxin: Impact of zinc on human health. Int. J. Environ. Res. Public Health 2010, 7, 1342-1365.

26. Weiss, J.H.; Hartley, D.M.; Koh, J.Y.; Choi, D.W. AMPA receptor activation potentiates zinc neurotoxicity. Neuron 1993, 10, 43-49.

27. Zhu, L.; Tang, Y.; Wang, H.D.; Zhang, Z.Y.; Pan, H. Immersion autometallographic demonstration of pathological zinc accumulation in human acute neural diseases. Neurol. Sci. 2012, 33, 855-861.

28. Adlard, P.A.; Bush, A.I. Metals and Alzheimer's disease. J. Alzheimers. Dis. 2006, 10, 145-163.

29. Kawahara, M.; Arispe, N.; Kuroda, Y.; Rojas, E. Alzheimer's disease amyloid B-protein forms $\mathrm{Zn}^{2+}$-sensitive, cation-selective channels across excised membrane patches from hypothalamic neurons. Biophys. J. 1997, 73, 67-75.

30. Lin, H.; Bhatia, R.; Lal, R. Amyloid beta protein forms ion channels: Implications for Alzheimer's disease pathophysiology. FASEB J. 2001, 15, 2433-2444.

31. Leach, S.P.; Salman, M.D.; Hamar, D. Trace elements and prion diseases: A review of the interactions of copper, manganese and zinc with the prion protein. Anim. Health Res. Rev. 2006, 7 , 97-105.

32. Valentine, J.S.; Hart, P.J. Misfolded CuZnSOD and amyotrophic lateral sclerosis. Proc. Natl. Acad. Sci. USA 2003, 100, 3617-3622.

33. Brewer, G.J. Recognition, diagnosis, and management of Wilson's disease. Proc. Soc. Exp. Biol. Med. 2000, 223, 39-46.

34. Koh, J.Y.; Choi, D.W. Zinc toxicity of cultured cortical neurons: Involvement of $\mathrm{N}$-methyl-D-asparatate receptors. Neuroscience 1994, 4, 1049-1057.

35. Kim, A.H.; Sheline, C.T.; Tian, M.; Higashi, T.; McMahon, R.J.; Cousins, R.J.; Choi, D.W. L-type $\mathrm{Ca}^{2+}$ channel-mediated $\mathrm{Zn}^{2+}$ toxicity and modulation by $\mathrm{ZnT}-1$ in PC12 cells. Brain Res. 2000, 886, 99-107.

36. Lee, J.Y.; Kim, Y.H.; Koh, J.Y. Protection by pyruvate against transient forebrain ischemia in rats. J. Neurosci. 2001, 21, RC171. 
37. Sheline, C.T.; Behrens, M.M.; Choi, D.W. Zinc-induced cortical neuronal death: Contribution of energy failure attributable to loss of $\mathrm{NAD}(+)$ and inhibition of glycolysis. J. Neurosci. 2000, 20, 3139-3146.

38. Sensi, S.L.; Ton-That, D.; Sullivan, P.G.; Jonas, E.A.; Gee, K.R.; Kaczmarek, L.K.; Weiss, J.H. Modulation of mitochondrial function by endogenous $\mathrm{Zn}^{2+}$ pools. Proc. Natl. Acad. Sci. USA 2003, 100, 6157-6162.

39. Kawahara, M.; Kato-Negishi, M.; Hosoda, R.; Kuroda, Y. Characterization of zinc-induced apoptosis of GT1-7 cells. Biomed. Res. Trace Elements 2002, 13, 280-281.

40. Konoha, K.; Sadakane, Y.; Kawahara, M. Effects of gadolinium and other metal on the neurotoxicity of immortalized hypothalamic neurons induced by zinc. Biomed. Res. Trace Elements 2004, 15, 275-277.

41. Kim, E.Y.; Chang, S.Y.; Chung, J.M.; Ryu, B.R.; Joo, C.K.; Moon, H.S.; Kang, K.; Yoon, S.H.; Han, P.L.; Gwag, B.J. Attenuation of $\mathrm{Zn}^{2+}$ neurotoxicity by aspirin: Role of $\mathrm{N}$-type $\mathrm{Ca}^{2+}$ channel and the carboxyl acid group. Neurobiol. Dis. 2001, 8, 774-783.

42. Kawahara, M.; Sadakane, Y.; Koyama, H.; Konoha, K.; Ohkawara, S. D-Histidine and L-histidine attenuate zinc-induced neuronal death in GT1-7 cells. Metallomics 2013, 5, 453-460.

43. Brown, M.K.; Naidoo, N. The endoplasmic reticulum stress response in aging and age-related diseases. Front. Physiol. 2012, 3, 263.

44. Ferreiro, E.; Baldeiras, I.; Ferreira, I.L.; Costa, R.O.; Rego, A.C.; Pereira, C.F.; Oliveira, C.R. Mitochondrial- and endoplasmic reticulum-associated oxidative stress in Alzheimer's disease: From pathogenesis to biomarkers. Int. J. Cell Biol. 2012, 2012, doi:10.1155/2012/735206.

45. Roussel, B.D.; Kruppa, A.J.; Miranda, E.; Crowther, D.C.; Lomas, D.A.; Marciniak, S.J. Endoplasmic reticulum dysfunction in neurological disease. Lancet Neurol. 2013, 12, 105-118.

46. Moskalev, A.A.; Smit-McBride, Z.; Shaposhnikov, M.V.; Plyusnina, E.N.; Zhavoronkov, A.; Budovsky, A.; Tacutu, R.; Fraifeld, V.E. Gadd45 proteins: Relevance to aging, longevity and age-related pathologies. Ageing Res. Rev. 2012, 11, 51-66.

47. Van Prooyen, N.; Andresen, V.; Gold, H.; Bialuk, I.; Pise-Masison, C.; Franchini, G. Hijacking the T-cell communication network by the human T-cell leukemia/lymphoma virus type 1 (HTLV-1) p12 and p8 proteins. Mol. Aspects Med. 2010, 31, 333-343.

48. Goruppi, S.; Iovanna, J.L. Stress-inducible protein p8 is involved in several physiological and pathological processes. J. Biol. Chem. 2010, 285, 1577-1581.

49. Onoue, S.; Kumon, Y.; Igase, K.; Ohnishi, T.; Sakanaka, M. Growth arrest and DNA damage-inducible gene 153 increases transiently in the thalamus following focal cerebral infarction. Brain Res. Mol. Brain Res. 2005, 134, 189-197.

50. Kunizuka, H.; Kinouchi, H.; Arai, S.; Izaki, K.; Mikawa, S.; Kamii, H.; Sugawara, T.; Suzuki, A.; Mizoi, K.; Yoshimoto, T. Activation of Arc gene, a dendritic immediate early gene, by middle cerebral artery occlusion in rat brain. Neuroreport 1999, 10, 1717-1722.

51. Rickhag, M.; Teilum, M.; Wieloch, T. Rapid and long-term induction of effector immediate early genes (BDNF, Neuritin and Arc) in peri-infarct cortex and dentate gyrus after ischemic injury in rat brain. Brain Res. 2007, 1151, 203-210.

52. Bonfanti, L.; Peretto, P.; De Marchis, S.; Fasolo, A. Carnosine-related dipeptides in the mammalian brain. Prog. Neurobiol. 1999, 59, 333-353. 
53. De Marchis, S.; Modena, C.; Peretto, P.; Giffard, C.; Fasolo, A. Carnosine-like immunoreactivity in the central nervous system of rats during postnatal development. J. Comp. Neurol. 2000, 426, 378-390.

54. Stuerenburg, H.J. The roles of carnosine in aging of skeletal muscle and in neuromuscular disease. Biochemistry (Mosc) 2000, 65, 862-865.

(C) 2013 by the authors; licensee MDPI, Basel, Switzerland. This article is an open access article distributed under the terms and conditions of the Creative Commons Attribution license (http://creativecommons.org/licenses/by/3.0/). 